\title{
The burden of hepatitis $C$ in Europe from the patients' perspective: a survey in 5 countries
}

\author{
Jeffrey Vietri ${ }^{*}$, Girish Prajapati ${ }^{2}$ and Antoine C El Khoury ${ }^{3}$
}

\begin{abstract}
Background: Few studies have examined the impact of Hepatitis $\mathrm{C}$ virus (HCV) infection on patient reported outcomes in Europe. This study was conducted to assess the burden of HCV infection in terms of work productivity loss, activity impairment, health-related quality of life, healthcare resource utilization, and associated costs.

Methods: The 2010 European National Health and Wellness Survey $(n=57,805)$ provided data. Patients reporting HCV infection in France, Germany, the UK, Italy, and Spain were matched to respondents without HCV using propensity scores. Outcome measures included the Work Productivity and Activity Impairment (WPAl) questionnaire and the Medical Outcomes Study Short Form-12 (SF-12v2) questionnaire. Subgroup analyses focused on treatment-naïve patients.

Results: HCV Patients ( $n=286$ ) had more work impairment (30\% vs. $18 \%, p<.001)$, more impairment in non-work activities (34\% vs. $28 \%, p<.05)$, and more annual physician visits per patient (19.8 vs. $13.3, p<.001)$. Estimated indirect and direct costs were $€ 2,956(p<.01)$ and $€ 495(p<.001)$ higher than in matched controls, respectively. Health-related quality of life was also lower among HCV patients. Treatment-naïve HCV patients $(n=139)$ also reported higher work impairment ( $29 \%$ vs. $15 \%, p<.01)$, as well as more frequent physician visits (19.5 vs. 12.1, $p<.01)$ than matched controls. Each treatment-naïve HCV infected patient incurred $€ 934$ in direct costs vs. $€ 508$ $(p<.01$ in matched controls. Employed treatment-naive patients reported higher productivity loss per year compared to matched controls (€6,414 vs. $€ 3,642, p<.05$ ).
\end{abstract}

Conclusion: HCV infection in Europe is associated with considerable economic and humanistic burden. This is also true of diagnosed patients who have never been treated for HCV.

Keywords: Hepatitis C virus, Absenteeism, Presenteeism, Work impairment, Costs, Health status

\section{Background}

An estimated 160 million people are chronically infected with Hepatitis $\mathrm{C}$ virus (HCV) worldwide [1]. Approximately 9 million have $\mathrm{HCV}$ infection in Europe, with greater prevalence in the southern and eastern regions [2-6]. While the incidence of new cases is low, few patients exposed to the virus spontaneously clear the infection, so exposure typically results in chronic infection that will continue indefinitely. Many chronically infected patients do not know that they have been infected with $\mathrm{HCV}$, as infection is largely asymptomatic [7].

Though chronic HCV infection does not always cause serious health consequences, patients are at greater risk

\footnotetext{
* Correspondence: Jeffrey.vietri@kantarhealth.com

'Health Outcomes Practice, Kantar Health, Independence Way Suite 220, Princeton, NJ, USA

Full list of author information is available at the end of the article
}

for development of cirrhosis, liver failure, and hepatocellular carcinoma (HCC), all of which are associated with high morbidity and mortality [8,9]. HCV infection is the most common indication for liver transplantation in Europe, and HCV infection of the transplanted liver is common. HCV was estimated to have caused more than 86,000 deaths in Europe in 2002 [4], a figure expected to increase as the patient population reaches the age at which long-term consequences of chronic infection typically manifest $[4,10-12]$.

The goal of treatment for $\mathrm{HCV}$ is sustained virologic response (SVR), when the virus cannot be detected in the blood six months after the end of treatment. Patients who achieve SVR are at much lower risk for cirrhosis and HCC than those who do not achieve virological cure [13]. However, treatment with pegylated interferon and 
ribavirin is often unsuccessful, and is associated with adverse events and patient burden during the course of treatment [14-16]. Newly developed treatments for HCV infection are expected to dramatically increase the rate of SVR [17], and determining whether novel treatments are cost effective requires an assessment of the burden of $\mathrm{HCV}$ infection, including the economic impact as well as any impairment of quality of life.

Research using the US National Health and Wellness Survey (NHWS) has documented a significant burden of $\mathrm{HCV}$ infection on work productivity, with infected respondents missing approximately $9 \%$ of working hours in the last week, and reporting an average of $27 \%$ impairment while at work [18], and a database study found that $\mathrm{HCV}$ infected patients were $7.5 \%$ less productive based on work units per hour [19]. HCV is also associated with increased use of healthcare resources and increased direct healthcare costs [19-24]. The estimates of healthcare resource use vary greatly. DiBonventura et al. reported approximately $30 \%$ more physician visits among patients with diagnosed $\mathrm{HCV}$ infection than among propensity matched controls, with a similar trend for emergency room (ER) visits [24]. Database studies looking at costs in the year following diagnosis of $\mathrm{HCV}$ infection have found even larger differences. Davis et al. found that all-cause healthcare claims in HCV infected patients were, on average, almost US\$21,000 in the year after diagnosis, nearly four times that in age, gender, and plan-matched controls [20], while McCombs et al. found an average cost of over US\$37,000 in the year following diagnosis, which represents an incremental cost of more than US\$23,000 [22]. Impaired health-related quality of life (HRQoL) in HCV population has also been documented [24-26]. However, almost all of these studies have focused on the US population, with very few studies describing the burden among HCV infected patients in Europe [26,27], and none from a patient perspective using a representative sample.

The objective of this study was to quantify the burden of $\mathrm{HCV}$ infection with respect to work productivity, healthcare resource use, related monetary cost to society, impairment in non-work activities, and HRQoL using a broadly representative sample of European adults.

\section{Methods}

The National Health and Wellness Survey (NHWS; Kantar Health, New York, NY, USA), is an annual, cross-sectional survey of adults aged 18 years or older, with 57,805 respondents across France, Germany, Italy, Spain, and the UK in 2010. The NHWS is a selfadministered survey which includes questions regarding diagnosed medical conditions, experience with over-thecounter and prescription medical treatments, healthrelated outcomes, as well as health-related attitudes and behaviors. Heath outcomes, including work productivity, impairment in activities of daily living, and HRQoL are assessed by validated scales (discussed below), and patients self-report the type and number of healthcare resources used during the six months preceding the survey. Potential respondents to the NHWS are recruited through an existing consumer panel selected by using opt-in emails, co-registration with panel partners, enewsletter campaigns, and online banner placements. All panelists must explicitly agree to be a panel member, register with the panel through a unique email address, and complete an in-depth demographic registration profile. The sample is generated through stratified random sampling within this panel, with quotas based on gender and age to ensure the final sample is representative of each country's adult (18 years of age and older) population. The 2010 NHWS was approved by Essex Institutional Review Board (Lebanon, NJ, USA), and all respondents provided informed consent.

For the present analysis, patients reporting Hepatitis B virus (HBV) infection, HIV, or AIDS were excluded to ensure that any burden documented in the $\mathrm{HCV}$ group was not due to $\mathrm{HCV}$-associated comorbidities rather than the $\mathrm{HCV}$ itself. Likewise, because $\mathrm{HCV}$ infected patients are likely to differ from individuals without $\mathrm{HCV}$ in ways that may affect the outcomes measured by the survey, a propensity scoring methodology was employed to match each $\mathrm{HCV}$ infected patient with a single member of the control group [28]. Country of residence, age, gender, sexual orientation (heterosexual, homosexual, bisexual, or decline to answer), education (high school graduate vs. below), income (above or below median for country), number of non-liver comorbidities, smoking (yes/no), exercise (yes vs. no), alcohol use (yes vs. no), and BMI (underweight, normal weight, overweight, obese, or decline to answer) were included in a logistic regression to predict a self-reported physician diagnosis of $\mathrm{HCV}$ infection. The estimates resulting from this regression-the propensity scores-indicated how likely each $\mathrm{HCV}$ patient and non-HCV respondent was to have HCV given their demographic and health characteristics. The widely-used greedy matching algorithm was used to match each HCV patient to a single non-HCV control in the same country whose propensity score most closely matched the patent's score [29].

The Work Productivity and Activity Impairment (WPAI) questionnaire was used to measure the impact of health on work performance [30]. The WPAI is a 6 -item validated instrument that consists of four metrics: absenteeism (the percentage of work time missed because of one's health), presenteeism (the percentage of impairment experienced while at work because of one's health), overall work productivity loss (an overall impairment estimate that is a combination of absenteeism and presenteeism), and activity 
impairment (the percentage of impairment in daily activities because of one's health). The recall period for all items is seven days. Only respondents who reported being employed full-time, employed part-time, or self-employed were shown the items assessing absenteeism, presenteeism, and overall work impairment, but all respondents provided data for activity impairment. Absenteeism was calculated by dividing the number of work hours a patient missed in the past week because of his or her health by the total number of hours a patient could have worked (the number of hours he/she did work plus the number of hours missed because of his/her health). Presenteeism was computed from patient's rating of his or her level of impairment experienced while at work in the past 7 days on a scale from 0 (no impairment) to 10 (completely unable to function), which was then divided by 10 to create a percentage, with a range from $0 \%$ to $100 \%$. Overall work impairment was measured by adding absenteeism and presenteeism to determine the total percentage of lost work time. Activity impairment was derived from patient's rating of the level of impairment experienced in daily activities in the past 7 days on a scale from 0 (no impairment) to 10 (completely unable to function), which was then divided by 10 to create a percentage, with a range from 0 to $100 \%$.

The 2010 NHWS also asked respondents about their use of healthcare resources over the preceding six months. Items included were the number of visits to healthcare providers and emergency room (ER), and hospitalization for the patient's own medical condition. Healthcare providers include general practitioner/family practitioners, internists and dentists as well as more specialized physicians. The reported values were doubled to obtain an annual estimate.

We estimated direct healthcare costs for each NHWS respondent, and indirect costs for each employed respondent. Direct costs were estimated by multiplying the annualized healthcare resource use by the average cost of that service reported in the literature [31], then adjusting for inflation using the Harmonized Consumer Prices Index to 2010 values [32]. Indirect costs were estimated by projecting each patient's absenteeism and presenteeism into an estimate of hours of lost productivity per year. Lost hours were then multiplied by an estimated hourly wage for each respondent. Hourly wages for all employed respondents (fulltime, part-time, and self-employed) were calculated using the median wage of full-time workers using the most recently available (2006) personal income figures from Eurostat for full-time employees in each country [33]. These were inflated to 2010 values by inflating them according to the percentage rise in adjusted household income in each country from 2006 to 2010 as reported by Eurostat for the continental European countries, and by the rise in personal income from 2006-2010 for the UK as reported by the Office of National Statistics. The yearly wage was divided by the number of weeks typically worked each year to estimate the weekly value of the individual's labor while at work. This weekly figure was then divided by the number of hours in a work week to create an hourly estimate. Figures for weeks and hours worked were obtained from the European Foundation for the Improvement of Living and Working Conditions [34].

The Medical Outcomes Study 12-Item Short Form Survey Instrument (SF-12v2) was used to assess HRQoL [35]. The instrument is designed to accurately report on eight health concepts (physical functioning, role physical, bodily pain, general health, vitality, social functioning, role emotional, and mental health) using the fewest questions possible. The SF-12 questions were selected from the widely used SF-36 health survey. The SF-12 allows calculation of physical component summary (PCS) and mental component summary (MCS) scores comparable to the ones calculated from SF-36. The present analysis included the PCS and MCS normbased scores, which are scaled to have a mean of 50 and a standard deviation of 10 in the US population. Consequently, a 3 to 5 -point difference is typically considered clinically significant [36-38]. In addition to generating summary PCS and MCS scores, the SF-12 can also be used to generate health state utilities using the SF-6D algorithm. The SF-6D is a preference-based single index measure for health using general population values [39]. The 18,000 health states that the SF-6D is able to describe are correlated with preference weights obtained from a sample of the UK general population using the recognized standard gamble valuation technique. The SF-6D index has interval scoring properties and yields summary scores on a theoretical $0-1$ scale, where 0 is a state equivalent to death, and 1 is equivalent to perfect health. A .03 point difference is typically considered the minimally clinically important difference [40].

\section{Statistical analysis}

Mean and standard deviation were calculated for all continuous measures, and frequencies and percentages were computed for categorical variables. Comparisons between HCV infected patients and controls (unmatched and matched) were made using chi-square tests for categorical outcomes and independent-samples t-tests for continuous outcomes. Because distributions of work impairment, activity impairment, and healthcare resource utilization were positively skewed, the Mann-Whitney $\mathrm{U}$ test was used in lieu of the $t$-test. An error rate of 5\% was adopted for all hypothesis tests, which were conducted in SPSS version 19.0.

\section{Results}

Of the 57,805 respondents in the 2010 European NHWS, 633 reported HBV, HIV, or AIDS, and were excluded from the sample. An additional 6 individuals 
were excluded because they reported HCV infection but indicated they had not been diagnosed by a physician. This resulted in a total sample size of 57,166 , of which 286 reported a physician diagnosis of $\mathrm{HCV}$. Of those reporting a diagnosis, 36 (12.6\%) reported currently receiving prescription treatment for $\mathrm{HCV}$, an additional $111(38.8 \%)$ reported receiving prescription treatment in the past, and 250 (48.6\%) reported never receiving prescription treatment. The 56,880 respondents who did not report ever experiencing $\mathrm{HCV}$ served as an unmatched control group.

As displayed in Table 1, HCV infected patients differed in a variety of ways from the non-HCV respondents in the European NHWS. Those with HCV infection were less likely to come from the UK or Germany, and more likely to come from Italy and Spain, consistent with the differences in $\mathrm{HCV}$ prevalence in those countries (all $\mathrm{p}<.05$ ). HCV infected patients were older (53 vs. $46, \mathrm{p}<.001$ ), more likely to be male $(58 \%$ vs. $48 \%, \mathrm{p}<.001)$, or smoke cigarettes ( $46 \%$ vs. $28 \%, \mathrm{p}<.001$ ), and were less likely to decline to report their sexual orientation $(2 \%$ vs. $4 \%, \mathrm{p}<.001)$ or drink alcohol (68\% vs. $79 \%, \mathrm{p}<.001)$, although over two-thirds of the HCV infected patients reported doing so. HCV infected patients also had more co-morbid conditions, excluding liver disease (.69 vs. $.27, \mathrm{p}<.01)$.

$\mathrm{HCV}$ patients generally reported worse outcomes than unmatched controls, presented in Table 2. HCV infected patients reported more impairment on all measures of work and activity impairment than unmatched control patients (all $\mathrm{p}<.001$ ). Likewise, HCV patients also used more healthcare resources across all categories (all $\mathrm{p}<.01$ ). The higher work productivity impairments and healthcare resource use observed among $\mathrm{HCV}$ patients resulted in higher estimated costs $($ all $\mathrm{p}<.01)$, presented in Table 3 . $\mathrm{HCV}$ patients also had significantly worse HRQoL than non-HCV patients on all measures (all $\mathrm{p}<.001$ ).

There were no significant differences on demographics between $\mathrm{HCV}$ infected patients and propensity matched controls (data not presented), though many of the decrements in outcomes associated with HCV remained significant (Table 2). Among HCV infected patients who reported being employed, health problems resulted in missing $43 \%$ more work than controls $(7.8 \%$ vs. $5.5 \%$, $\mathrm{p}<.05$ ), and $80 \%$ greater impairment while at work ( $26.3 \%$ vs. $14.5 \%, \mathrm{p}<.001$ ), leading to $66 \%$ greater overall work impairment $(30.5 \%$ vs. $18.3 \%, \mathrm{p}<.001)$. Likewise, $\mathrm{HCV}$ was associated with greater impairment in nonwork activities $(34.4 \%$ vs. $28.5 \%, \mathrm{p}<.05)$.

$\mathrm{HCV}$ patients also had more physician visits per year than matched controls $(19.8$ vs.13.3, $\mathrm{p}<.001)$. However, lack of power prevented the detection of differences between $\mathrm{HCV}$ patients and controls for annual ER visits $(.68$ vs. $.39, \mathrm{p}=.33)$ and hospitalizations (.52 vs. .27 , $\mathrm{p}=.07)$, though these differences were of a similar
Table 1 Demographic and health characteristics of the sample by HCV status

\begin{tabular}{|c|c|c|c|c|c|}
\hline \multirow[b]{3}{*}{ Variable } & \multirow{2}{*}{\multicolumn{2}{|c|}{$\begin{array}{c}\text { HCV group } \\
(n=286)\end{array}$}} & \multirow{2}{*}{\multicolumn{2}{|c|}{$\begin{array}{c}\begin{array}{c}\text { Unmatched } \\
\text { control } \\
\text { group }\end{array} \\
(n=56,880)\end{array}$}} & \multirow[t]{3}{*}{ p-value } \\
\hline & & & & & \\
\hline & $\mathrm{n}$ & $\%$ & $\mathrm{n}$ & $\%$ & \\
\hline \multicolumn{6}{|l|}{ Country } \\
\hline France & 66 & $23.1 \%$ & 14835 & $26.1 \%$ & .248 \\
\hline Germany & 60 & $21.0 \%$ & 14859 & $26.1 \%$ & .048 \\
\hline UK & 39 & $13.6 \%$ & 14919 & $26.2 \%$ & $<.001$ \\
\hline Italy & 83 & $29.0 \%$ & 7358 & $12.9 \%$ & $<.001$ \\
\hline Spain & 38 & $13.3 \%$ & 4909 & $8.6 \%$ & .005 \\
\hline Female & 119 & $41.6 \%$ & 29352 & $51.6 \%$ & .001 \\
\hline \multicolumn{6}{|l|}{ Sexual orientation } \\
\hline Heterosexual & 253 & $88.5 \%$ & 50937 & $89.6 \%$ & .548 \\
\hline Homosexual & 11 & $3.8 \%$ & 1306 & $2.3 \%$ & .081 \\
\hline Bi-sexual & 17 & $5.9 \%$ & 2311 & $4.1 \%$ & .108 \\
\hline Decline to answer & 5 & $1.7 \%$ & 2326 & $4.1 \%$ & .046 \\
\hline Married/living with partner & 167 & $58.40 \%$ & 36168 & $63.6 \%$ & .069 \\
\hline High school graduate & 243 & $85.0 \%$ & 46911 & $82.5 \%$ & .269 \\
\hline \multicolumn{6}{|l|}{ Income } \\
\hline Above median & 133 & $46.5 \%$ & 25058 & $44.1 \%$ & .405 \\
\hline Below median & 117 & $40.9 \%$ & 23482 & $41.3 \%$ & .898 \\
\hline Decline to answer & 36 & $12.6 \%$ & 8340 & $14.7 \%$ & .322 \\
\hline \multicolumn{6}{|l|}{ BMI } \\
\hline Underweight & 8 & $2.8 \%$ & 1590 & $2.8 \%$ & .998 \\
\hline Normal & 107 & $37.4 \%$ & 24002 & $42.4 \%$ & .102 \\
\hline Overweight & 108 & $37.8 \%$ & 18858 & $33.3 \%$ & .099 \\
\hline Obese & 62 & $21.7 \%$ & 10899 & $19.2 \%$ & .281 \\
\hline Decline to answer & 1 & $0.4 \%$ & 1531 & $2.7 \%$ & .014 \\
\hline Currently drink & 194 & $67.8 \%$ & 44797 & $78.8 \%$ & $<.001$ \\
\hline Currently exercise & 153 & $53.5 \%$ & 32373 & $56.9 \%$ & .244 \\
\hline \multirow[t]{2}{*}{ Currently smoke } & 131 & $45.8 \%$ & 16058 & $28.2 \%$ & $<.001$ \\
\hline & Mean & SD & Mean & SD & \\
\hline Age & 52.82 & 13.49 & 46.40 & 15.82 & $<.001$ \\
\hline $\begin{array}{l}\text { Number of co-morbid } \\
\text { conditions }\end{array}$ & .69 & 1.04 & .27 & .67 & .008 \\
\hline
\end{tabular}

magnitude as the significant differences between $\mathrm{HCV}$ patients and the unmatched non-HCV sample.

Costs were also estimated to be higher among $\mathrm{HCV}$ patients (Table 3). Employed HCV patients lost an average of $€ 1,914$ worth of productivity to absenteeism per year, $60 \%$ more than their matched controls $(€ 1,195$, $\mathrm{p}<.05$ ). Impairment while at work (presenteeism) is also significantly more costly in $\mathrm{HCV}$ patients than controls, with annual productivity losses averaging $€ 5,268$ and $€ 3,154(\mathrm{p}<.05)$, respectively, for an overall indirect cost 
Table 2 Health outcomes among HCV patients and controls

\begin{tabular}{|c|c|c|c|c|c|c|c|c|}
\hline & \multirow{2}{*}{\multicolumn{2}{|c|}{$\begin{array}{c}\text { HCV group } \\
(n=286)\end{array}$}} & \multirow{2}{*}{\multicolumn{3}{|c|}{$\begin{array}{c}\text { Unmatched controls } \\
(n=56,880)\end{array}$}} & \multirow{2}{*}{\multicolumn{3}{|c|}{$\begin{array}{c}\text { Matched controls } \\
(n=286)\end{array}$}} \\
\hline & & & & & & & & \\
\hline & Mean & SD & Mean & SD & p-value* & Mean & SD & p-valuet \\
\hline \multicolumn{9}{|l|}{ Work impairment } \\
\hline Absenteeism & $7.78 \%$ & $19.16 \%$ & $5.44 \%$ & $19.20 \%$ & $<.001$ & $5.45 \%$ & $20.34 \%$ & .010 \\
\hline Presenteeism & $26.27 \%$ & $27.58 \%$ & $15.83 \%$ & $22.79 \%$ & $<.001$ & $14.45 \%$ & $21.58 \%$ & $<.001$ \\
\hline Overall work impairment & $30.45 \%$ & $31.42 \%$ & $19.39 \%$ & $27.70 \%$ & $<.001$ & $18.30 \%$ & $27.47 \%$ & $<.001$ \\
\hline Activity impairment & $34.37 \%$ & $30.60 \%$ & $24.38 \%$ & $28.16 \%$ & $<.001$ & $28.46 \%$ & $30.57 \%$ & .011 \\
\hline \multicolumn{9}{|l|}{ Healthcare use } \\
\hline Annual physician visits & 19.80 & 23.93 & 10.66 & 14.64 & $<.001$ & 13.26 & 19.21 & $<.001$ \\
\hline Annual ER visits & 0.68 & 2.11 & 0.38 & 1.90 & .006 & 0.39 & 1.19 & .330 \\
\hline Annual hospitalizations & 0.52 & 1.59 & 0.26 & 2.14 & $<.001$ & 0.27 & 0.98 & .073 \\
\hline \multicolumn{9}{|l|}{ Quality of life (SF-12v2) } \\
\hline MCS & 44.17 & 9.85 & 46.58 & 10.59 & $<.001$ & 46.36 & 10.79 & .012 \\
\hline PCS & 43.61 & 10.14 & 48.67 & 9.75 & $<.001$ & 46.09 & 10.33 & .004 \\
\hline Health utility & 0.67 & 0.12 & 0.73 & 0.13 & $<.001$ & 0.71 & 0.15 & .001 \\
\hline
\end{tabular}

Comparisons of work impairment include only the employed subsamples: 138 HCV patients, 32,179 non-HCV, and 134 matched controls.

*Indicates the significance comparing the HCV group with the unmatched control group.

tIndicates the significance comparing the HCV group with the matched control group.

of $€ 7,182$ per year, $€ 2,810$ more per employed patient per year than controls $(\mathrm{p}<.01$ for the difference). Direct costs were also significantly elevated among $\mathrm{HCV}$ patients, with annual costs $76 \%$ greater than matched controls $(€ 1,147$ vs. $€ 652, \mathrm{p}<.001)$, driven by significantly greater costs due to physician visits (€487 vs. $€ 330, \mathrm{p}<.001$ ) and hospitalization, though lack of power prevented the difference in hospitalization costs from reaching statistical significance ( $€ 589$ vs. $€ 280, \mathrm{p}<.08)$.

$\mathrm{HCV}$ infection also impacted the three measures of HRQoL. HCV patients had a clinically meaningful .04 decrement in health utilities compared to matched controls $(.67$ vs. .71, $\mathrm{p}<.01)$. MCS scores in $\mathrm{HCV}$ were about 2 points lower than matched controls (44.17 vs. 46.36, $\mathrm{p}<.05$ ), while PCS scores were about 2.5 points lower in HCV (43.61 vs. 46.36, p <.01), though these differences are slightly smaller than would be considered clinically meaningful.

\section{Treatment-naïve patients}

Worse outcomes were also seen among the treatmentnaïve subgroup $(n=139)$ relative to matched controls.

Table 3 Costs among HCV patients and controls

\begin{tabular}{|c|c|c|c|c|c|c|c|c|}
\hline & \multirow{2}{*}{\multicolumn{2}{|c|}{$\begin{array}{c}\text { HCV Patients } \\
(\mathrm{n}=286)\end{array}$}} & \multirow{2}{*}{\multicolumn{3}{|c|}{$\begin{array}{c}\text { Non-HCV } \\
(n=56,880)\end{array}$}} & \multirow{2}{*}{\multicolumn{3}{|c|}{$\begin{array}{c}\text { Matched controls } \\
(n=286)\end{array}$}} \\
\hline & & & & & & & & \\
\hline & Mean & SD & Mean & SD & p-value* & Mean & SD & p-value ${ }^{\dagger}$ \\
\hline \multicolumn{9}{|l|}{ Indirect costs } \\
\hline Absenteeism & $€ 2,038.63$ & $€ 6,048.12$ & $€ 1,357.90$ & $€ 5,326.81$ & $<.001$ & $€ 1,253.43$ & $€ 4,884.92$ & .011 \\
\hline Presenteeism & $€ 5,493.91$ & $€ 6,898.97$ & $€ 3,368.88$ & $€ 5,479.10$ & $<.001$ & $€ 3,298.06$ & $€ 5,454.64$ & .001 \\
\hline Total indirect & $€ 7,532.54$ & $€ 9,879.57$ & $€ 4,729.20$ & $€ 7,786.24$ & $<.001$ & $€ 4,576.29$ & $€ 7,365.19$ & .002 \\
\hline \multicolumn{9}{|l|}{ Direct costs } \\
\hline Physician visits & $€ 486.61$ & $€ 649.61$ & $€ 288.54$ & $€ 410.89$ & $<.001$ & $€ 329.52$ & $€ 536.32$ & $<.001$ \\
\hline ER visits & $€ 71.68$ & $€ 233.24$ & $€ 40.72$ & $€ 207.97$ & .007 & $€ 42.94$ & $€ 137.86$ & .360 \\
\hline Hospitalizations & $€ 588.77$ & $€ 1,867.19$ & $€ 288.19$ & $€ 2,754.17$ & $<.001$ & $€ 279.62$ & $€ 991.20$ & .075 \\
\hline Total direct costs & $€ 1,147.06$ & $€ 2,265.46$ & $€ 617.45$ & $€ 2,889.90$ & $<.001$ & $€ 652.07$ & $€ 1,373.94$ & $<.001$ \\
\hline Total costs & $€ 4,587.54$ & $€ 8,653.64$ & $€ 3,291.01$ & $€ 7,154.33$ & $<.001$ & $€ 2,685.28$ & $€ 5,530.30$ & $<.001$ \\
\hline
\end{tabular}

Comparisons indirect costs include only the employed subsamples: $138 \mathrm{HCV}$ patients, 32,179 non-HCV, and 134 matched controls. Comparisons of direct and total costs include the full samples. Unemployed respondents' indirect costs are included in total costs as $€ 0$.

*Indicates the significance comparing the HCV group with the unmatched control group. †Indicates the significance comparing the HCV group with the matched control group. 
Employed treatment-naïve patients reported significantly greater work impairment than matched controls. As displayed in Table 4, untreated HCV infection was associated with nearly twice the impairment while at work (presenteeism; $24.8 \%$ vs. $12.9 \%, \mathrm{p}<.01$ ). Overall work impairment was elevated to a similar degree $(28.7 \%$ vs. $14.8 \%, \mathrm{p}<.01)$. However, the difference in absenteeism did not reach statistical significance $(6.7 \%$ vs. $2.4 \%$, $\mathrm{p}=.16)$. Impairment in non-work activities was also similar across HCV status ( $31.7 \%$ vs. $29.3 \%, \mathrm{p}=.38$ ).

Consistent with the trend observed in the larger $\mathrm{HCV}$ sample, treatment-naive patients also used more healthcare resources than matched controls. HCV patients used all forms of healthcare at least as much as matched controls. Significantly, patients had about $60 \%$ more physician visits than controls (19.5 vs. 12.1, $\mathrm{p}<.01)$. Differences in ER visits (.45 vs. $.35, \mathrm{p}=.97$ ) and hospitalizations ( .36 vs. $.19, \mathrm{p}=.12$ ) were not statistically significant.

The greater work impairment among employed treatment-naïve $\mathrm{HCV}$ patients is associated with significantly higher economic costs due to lost productivity. Table 5 shows the estimated value of the lost productivity. The incremental cost of HCV infection is $€ 2,773$ per employed patient per year, primarily because of greater presenteeism than matched controls. Likewise, more frequent healthcare use is reflected in higher estimated direct medical costs, which were greater to a significant degree for physician visits and total direct costs, incurring $€ 427$ more per year on average than matched

Table 4 Health outcomes in treatment-naïve HCV patients and matched controls

\begin{tabular}{|c|c|c|c|c|c|}
\hline & \multirow{2}{*}{\multicolumn{2}{|c|}{$\begin{array}{c}\text { HCV never } \\
\text { treated } \\
(n=139)\end{array}$}} & \multirow{2}{*}{\multicolumn{2}{|c|}{$\begin{array}{c}\text { Matched } \\
\text { controls } \\
(n=139)\end{array}$}} & \multirow[t]{3}{*}{ p-value } \\
\hline & & & & & \\
\hline & $M$ & SD & $M$ & SD & \\
\hline \multicolumn{6}{|c|}{ Work productivity \& activity impairment } \\
\hline Absenteeism & $6.67 \%$ & $18.26 \%$ & $2.84 \%$ & $13.36 \%$ & .157 \\
\hline Presenteeism & $24.84 \%$ & $30.07 \%$ & $12.86 \%$ & $21.28 \%$ & .006 \\
\hline Overall work impairment & $28.65 \%$ & $32.94 \%$ & $14.75 \%$ & $24.57 \%$ & .004 \\
\hline Activity impairment & $31.73 \%$ & $30.57 \%$ & $29.28 \%$ & $31.48 \%$ & .374 \\
\hline \multicolumn{6}{|l|}{ Healthcare resource utilization } \\
\hline Physician visits & 19.54 & 24.62 & 12.06 & 16.80 & .001 \\
\hline ER visits & 0.46 & 1.90 & 0.35 & 1.15 & .986 \\
\hline Hospitalizations & 0.36 & 1.16 & 0.19 & 0.99 & .120 \\
\hline \multicolumn{6}{|l|}{ Quality of life (SF-12v2) } \\
\hline MCS & 44.72 & 10.43 & 45.93 & 11.64 & .361 \\
\hline PCS & 43.49 & 10.26 & 45.99 & 10.72 & .048 \\
\hline Health utility & 0.68 & 0.13 & 0.71 & 0.15 & .080 \\
\hline
\end{tabular}

Comparisons of work productivity impairment are based on 65 treatmentnaïve HCV patients and 65 matched controls. All other comparisons include the entire samples.
Table 5 Estimated costs in treatment-naïve HCV patients and matched controls

\begin{tabular}{|c|c|c|c|c|c|}
\hline & \multirow{2}{*}{\multicolumn{2}{|c|}{$\frac{\text { HCV Never treated }}{(n=139)}$}} & \multirow{2}{*}{\multicolumn{2}{|c|}{$\begin{array}{c}\text { Matched controls } \\
(n=139)\end{array}$}} & \multirow{3}{*}{$\begin{array}{c}\mathrm{p}- \\
\text { value }\end{array}$} \\
\hline & & & & & \\
\hline & $M$ & SD & $M$ & SD & \\
\hline \multicolumn{6}{|l|}{ Indirect costs } \\
\hline Absenteeism & $€ 1,293.61$ & $€ 4,398.13$ & $€ 579.62$ & $€ 2,504.32$ & .204 \\
\hline Presenteeism & $€ 5,120.80$ & $€ 7,680.29$ & $€ 3,062.29$ & $€ 5,868.47$ & .015 \\
\hline $\begin{array}{l}\text { Total } \\
\text { indirect }\end{array}$ & $€ 6,414.42$ & $€ 8,587.96$ & $€ 3,641.91$ & $€ 6,699.54$ & .011 \\
\hline \multicolumn{6}{|l|}{ Direct costs } \\
\hline $\begin{array}{l}\text { Physician } \\
\text { visits }\end{array}$ & $€ 488.06$ & $€ 720.02$ & $€ 288.44$ & $€ 458.58$ & .003 \\
\hline ER visits & $€ 47.18$ & $€ 178.64$ & $€ 39.19$ & $€ 140.43$ & .979 \\
\hline Hospitalizations & $€ 399.05$ & $€ 1,368.76$ & $€ 179.88$ & $€ 858.29$ & .124 \\
\hline Total direct & $€ 934.30$ & $€ 1,873.33$ & $€ 507.50$ & $€ 1,053.43$ & .005 \\
\hline Total costs & $€ 3,834.44$ & $€ 6,991.25$ & $€ 2,119.56$ & $€ 4,974.79$ & $<.001$ \\
\hline
\end{tabular}

Indirect costs apply only to the $65 \mathrm{HCV}$ patients and 65 matched controls who report being employed. Direct and total costs apply to the entire sample. Unemployed respondents' indirect costs are included in total costs as $€ 0$.

controls. Overall, each treatment-naïve $\mathrm{HCV}$ patient was associated with an average overall incremental cost of $€ 1,715$ above the matched controls per year.

Treatment-naïve patients also reported worse mean physical quality of life than matched controls (43.49 vs. $45.99, \mathrm{p}<.05)$, though the magnitude of this effect is slightly below the level considered clinically meaningful. There was also a trend for patients to have lower health utilities (.68 vs. $71, \mathrm{p}=.08$ ), which would be considered clinically meaningful. The decrement on MCS scores associated with untreated $\mathrm{HCV}$ did not reach statistical significance (44.72 vs. $45.93, \mathrm{p}=.36$ ).

\section{Discussion}

The present study included data from a large survey of European adults with and without $\mathrm{HCV}$ infection across five counties, which measured outcomes through widely used validated scales. Patients reporting a physician diagnosis of $\mathrm{HCV}$ infection had significantly impaired work productivity, greater impairment in non-work activities, more healthcare resource utilization, and worse HRQoL than both the general population without $\mathrm{HCV}$ and propensity-matched individuals without $\mathrm{HCV}$ infection. The economic costs of $\mathrm{HCV}$ infection are considerable. We estimated work-productivity impairment due to HCV costs over $€ 7,500$ per employed patient per year, an incremental indirect cost of almost $€ 3,000$ over matched controls. Direct costs are also elevated by almost $€ 500$ per patient when compared to matched controls. The intangible cost of lower HRQoL observed 
in this sample was also significant, particularly regarding physical quality of life and health utility. HCV patients had consistently worse outcomes than matched controls across almost all outcome measures, though some measures of healthcare resource use did not reach significance. This seems to be primarily an issue of statistical power, as those that did not reach significance-ER visits and hospitalizations-were those measuring rare events experienced by a minority of respondents. A previous study using the same measures but using a larger, US sample found significant results, despite observing numerically smaller differences between $\mathrm{HCV}$ patients and controls [24]. Otherwise, the HRQoL decrements and work impairment observed in the present analysis are consistent with those measured in the US NHWS, and of a similar magnitude [18].

In addition to examining $\mathrm{HCV}$ infected patients as a whole, the present study also considered treatment-naïve patients separately. The treatment-naïve patients are an especially interesting subgroup, as they are neither burdened by the adverse events of treatment, nor benefited from a successful therapy, and so may better represent the burden of untreated $\mathrm{HCV}$ infection. Relative to matched controls, these patients reported greater impairment at work and more frequent physician visits, and estimated costs were also higher. Unlike treatmentexperienced patients, these individuals' elevated resource use would not be due to treatment or adverse events associated with such treatment, nor would work impairments or reduced HRQoL be due to side effects. The pattern of results in this subgroup was generally consistent with the findings in the broader comparisons, with few exceptions. Treatment-naïve patients did not show significantly elevated absenteeism relative to matched controls, but the magnitude of the difference was actually larger than in the broader comparison, suggesting that this difference is simply due to a lack of power rather than a different pattern among treatment-naïve patients.

The use of propensity scoring matching ensures that none of the effects observed could be attributed to any demographic or health history variables included in the matching analyses. However, we cannot rule out the possibility that additional variables (such as prior drug use) not included in the matching may explain the observed differences in health outcomes. However, most of the likely factors (co-morbid health conditions, health behaviors, etc.) were equated by the matching procedure.

The self-report survey methodology did not allow us to verify $\mathrm{HCV}$ diagnosis. However, the findings coincide with those of previous studies, suggesting this HCV sample is similar to that of other, clinically-verified $\mathrm{HCV}$ samples. We were also unable to confirm that controls were free of $\mathrm{HCV}$ infection, and given that many $\mathrm{HCV}$ patients are unaware of the infection it is possible that $\mathrm{HCV}$ patients were in the control group, causing us to underestimate the impact of $\mathrm{HCV}$ infection. The current study did not assess reasons for healthcare resource utilization but, given the propensity score methodology, the assumption was made that the additional resources used by the HCV group were due to the virus itself, as none of the assessed demographic or non-HCV health history variables differed between the groups. Some selection bias may also be present, in that individuals who completed the survey may have differed in some meaningful way from those who did not respond. However, for such a bias to affect the conclusions, the effect of $\mathrm{HCV}$ would have to be different among those who chose not to complete the survey than in those who did respond, which seems unlikely. Finally, the modest number of $\mathrm{HCV}$ infected respondents limits the precision of the estimates of the associated burden, though this would not contribute to spurious positive findings.

\section{Conclusions}

The humanistic and economic burden of HCV in Europe is substantial. The pattern of results is similar among treatment-naïve patients, which suggests that the burden of treatment is not driving the elevated resource use and lower HRQoL observed in the broader sample. Effective treatment of HCV may alleviate the work impairment associated with $\mathrm{HCV}$ and lower use of healthcare resources, while providing improved quality of life to the individual.

\section{Competing interests}

Merck \& Co. funded the analysis for this study, and markets a treatment for hepatitis $C$ infection. JV is an employee of Kantar Health, which conducted the study with funding from Merck \& Co. ACEK was an employee of Merck \& Co. at the time the study was completed, and GP is a contractor to Merck \& Co.

\section{Authors' contributions}

JV and ACEK conceived the study. JV conducted the data analysis. All authors reviewed the results and contributed to the writing of the final manuscript.

\section{Author details}

${ }^{1}$ Health Outcomes Practice, Kantar Health, Independence Way Suite 220 Princeton, NJ, USA. ${ }^{2}$ AllSource PPS, Long Beach, CA, USA. ${ }^{3}$ Merck \& Co., West Point, PA, USA.

Received: 29 May 2012 Accepted: 9 January 2013

Published: 17 January 2013

\section{References}

1. Lavanchy D: Evolving epidemiology of hepatitis $C$ virus. Clin Microbiol Infect 2011, 17:107-115.

2. Palitzsch KD, Hottentrager B, Schlottmann K, Frick E, Holstege A, Scholmerich J, Jilg W: Prevalence of antibodies against hepatitis $C$ virus in the adult German population. Eur J Gastroenterol Hepatol 1999, 11:1215-1220.

3. Hatzakis A, Wait S, Bruix J, Buti M, Carballo M, Cavaleri M, Colombo M, Delarocque-Astagneau E, Dusheiko G, Esmat G, et al: The state of hepatitis $B$ and $C$ in Europe: report from the hepatitis $B$ and $C$ summit

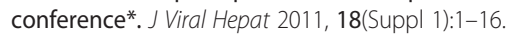


4. Muhlberger N, Schwarzer R, Lettmeier B, Sroczynski G, Zeuzem S, Siebert U: HCV-related burden of disease in Europe: a systematic assessment of incidence, prevalence, morbidity, and mortality. BMC Public Health 2009, 9:34

5. Sy T, Jamal MM: Epidemiology of hepatitis $\mathrm{C}$ virus (HCV) infection. Int J Med Sci 2006, 3:41-46.

6. Shepard CW, Finelli L, Alter MJ: Global epidemiology of hepatitis C virus infection. Lancet Infect Dis 2005, 5:558-567.

7. Seeff LB: Natural history of chronic hepatitis C. Hepatology 2002, 36:S35-S46.

8. McHutchison JG, Bacon BR, Owens GS: Making it happen: managed care considerations in vanquishing hepatitis C. Am J Manag Care 2007, 13:327.

9. Lauer GM, Walker BD: Hepatitis C virus infection. N Engl J Med 2001, 345:41-52.

10. Deuffic-Burban S, Mathurin P, Valleron AJ: Modelling the past, current and future HCV burden in France: detailed analysis and perspectives. Stat Methods Med Res 2009, 18:233-252.

11. Garcia-Fulgueiras A, Garcia-Pina R, Morant C, Garcia-Ortuzar V, Genova R, Alvarez E: Hepatitis C and hepatitis B-related mortality in Spain. Eur J Gastroenterol Hepatol 2009, 21:895-901.

12. Sweeting MJ, De Angelis D, Brant $L$, Harris HE, Mann AG, Ramsay ME: The burden of hepatitis C in England. J Viral Hepat 2007, 14:570-576.

13. Veldt BJ, Heathcote EJ, Wedemeyer H, Reichen J, Hofmann WP, Zeuzem S, Manns MP, Hansen BE, Schalm SW, Janssen HLA: Sustained virologic response and clinical outcomes in patients with chronic hepatitis $C$ and advanced fibrosis. Ann Intern Med 2007, 147:677.

14. Foster G: Hepatitis $C$ virus infection: quality of life and side effects of treatment. J Hepatol 1999, 31:250-254.

15. Brook RA, Kleinman NL, Su J, Corey-Lisle P, Iloeje UH: Absenteeism and productivity among employees being treated for Hepatitis $C$. Am J Manag Care 2011, 17:8.

16. Bianchi G, Loguercio C, Sgarbi D, Abbiati R, Chen C, Di Pierro M, Disalvo D, Natale $S$, Marchesini G: Reduced quality of life in patients with chronic hepatitis C: effects of interferon treatment. Dig Liver Dis 2000, 32:398-405.

17. Lange CM, Sarrazin C, Zeuzem S: Review article: specifically targeted anti-viral therapy for hepatitis $\mathrm{C}$ - a new era in therapy. Aliment Pharmacol Ther 2010, 32:14-28.

18. DiBonaventura M, Wagner JS, Yuan Y, L'Italien G, Langley P, Ray Kim W: The impact of hepatitis $C$ on labor force participation, absenteeism, presenteeism and non-work activities. J Med Econ 2011, 14:253-261.

19. Su J, Brook RA, Kleinman NL, Corey-Lisle P: The impact of hepatitis $C$ virus infection on work absence, productivity, and healthcare benefit costs. Hepatology 2010, 52:436-442.

20. Davis KL, Mitra D, Medjedovic J, Beam C, Rustgi V: Direct economic burden of chronic hepatitis $C$ virus in a United States managed care population. J Clin Gastroenterol 2011, 45:e17-e24.

21. Solomon M, Bonafede M, Pan K, Wilson K, Beam C, Chakravarti P, Spiegel B: Direct medical care costs among pegylated interferon plus ribavirintreated and untreated chronic hepatitis C patients. Dig Dis Sci 2011, 56:3024-3031

22. McCombs JS, Yuan Y, Shin J, Saab S: Economic burden associated with patients diagnosed with hepatitis C. Clin Ther 2011, 33:1268-1280.

23. Jhaveri $R$, Grant W, Kauf $T L$, McHutchison J: The burden of hepatitis $C$ virus infection in children: estimated direct medical costs over a 10-year period. J Pediatr 2006, 148:353-358.

24. DiBonaventura MD, Wagner JS, Yuan Y, L'Italien G, Langley P, Ray Kim W: Humanistic and economic impacts of hepatitis $C$ infection in the United States. J Med Econ 2010, 13:709-718.

25. Bonkovsky HL, Snow KK, Malet PF, Back-Madruga C, Fontana RJ, Sterling RK, Kulig CC, Di Bisceglie AM, Morgan TR, Dienstag JL: Health-related quality of life in patients with chronic hepatitis $C$ and advanced fibrosis. $J$ Hepatol 2007, 46:420-431.

26. Foster $\mathrm{G}$, Goldin R, Thomas $H$ : Chronic hepatitis $C$ virus infection causes a significant reduction in quality of life in the absence of cirrhosis. Hepatology 1998, 27:209-212

27. Bjornsson E, Verbaan H, Oksanen A, Fryden A, Johansson J, Friberg S Dalgard O, Kalaitzakis E: Health-related quality of life in patients with different stages of liver disease induced by hepatitis $C$. Scand J Gastroenterol 2009, 44:878-887.
28. Rosenbaum PR, Rubin DB: Constructing a control group using multivariate matched sampling methods that incorporate the propensity score. Am Statistician 1985, 39:33-38.

29. Parsons LS: Reducing bias in a propensity score matched-pair sample using greedy matching techniques. In Proceedings of the Twenty-Sixth Annual SAS Users Group Conference. Cary, NC: SAS Institute Inc; 2001:214-226

30. Reilly MC, Zbrozek AS, Dukes EM: The validity and reproducibility of a work productivity and activity impairment instrument. Pharmacoeconomics 1993, 4:353.

31. Williams A, Lloyd A, Watson L, Rabe K: Cost of scheduled and unscheduled asthma management in seven European Union countries. Eur Respir Rev 2006, 15:4.

32. Eurostat: GDP per capita in PPS. http://epp.eurostat.ec.europa.eu/tgm/table do?tab=table\&init=1\&plugin=1\&language=en\&pcode=tsieb060.

33. Brandolini A, Rosolia A, Torrini R: The distribution of employees' labour earnings in the EU: data, concepts and first results. Luxembourg; 2010.

34. Cabrita J, Ortigão M: Working time developments - 2010. Dublin, Ireland: European Foundation for the Improvement of Living and Working Conditions; 2011.

35. Ware J, Kosinski M, Turner-Bowker D, Gandek B: SF-12v2: How to score version 2 of the SF-12 health survey. Lincoln, Rhode Island: Quality Metric Incorporated Health Assessment Lab; 2002.

36. Norman GR, Sloan JA, Wyrwich KW: Interpretation of changes in healthrelated quality of life: the remarkable universality of half a standard deviation. Med Care 2003, 41:582

37. Farivar SS, Liu H, Hays RD: Half standard deviation estimate of the minimally important difference in HRQOL scores? Expert Rev Pharmacoecon Outcomes Res 2004, 4:515-523.

38. Samsa G, Edelman D, Rothman ML, Williams GR, Lipscomb J, Matchar D: Determining clinically important differences in health status measures: a general approach with illustration to the Health Utilities Index Mark II. Pharmacoeconomics 1999, 15:141-155.

39. Brazier J, Roberts J, Deverill M: The estimation of a preference-based measure of health from the SF-36. J Health Econ 2002, 21:271-292.

40. Walters SJ, Brazier JE: Comparison of the minimally important difference for two health state utility measures: EQ-5D and SF-6D. Qual Life Res 2005, 14:1523-1532.

\section{doi:10.1186/1471-230X-13-16}

Cite this article as: Vietri et al:: The burden of hepatitis $C$ in Europe from the patients' perspective: a survey in 5 countries. BMC Gastroenterology $201313: 16$

\section{Submit your next manuscript to BioMed Central and take full advantage of:}

- Convenient online submission

- Thorough peer review

- No space constraints or color figure charges

- Immediate publication on acceptance

- Inclusion in PubMed, CAS, Scopus and Google Scholar

- Research which is freely available for redistribution 